\title{
Anti-Glutamic Acid Decarboxylase Antibody in Graves' Disease Is A Possible Indicator for The Unlikelihood of Going into Remission with Antithyroid Agents
}

\author{
AI YOSHIHARA, OSAMU ISOZAKI, YUMIKO OKUBO AND KAZUE TAKANO
}

Department of Medicine, Institute of Clinical Endocrinology, Tokyo Women's Medical University

\begin{abstract}
The prevalence and titer of glutamic acid decarboxylase antibody (GADAb) in type 1 diabetes mellitus (T1DM) has been reported to be higher in patients with autoimmune thyroid diseases (AITD) than those without them. However, we have no data about the influence of GADAb on AITD. We therefore studied the clinical characteristics of Graves' disease (GD) with GADAb in order to clarify the influence of GADAb on GD. Twelve GD patients with GADAb were enrolled and were compared to $40 \mathrm{GD}$ patients without DM. The male to female ratio and age of onset of GD showed no statistical difference. The titer of TSH receptor antibody (TRAb) at the onset of GD was similar in both groups. Initial treatment with methimazole (MMI) was started in all patients with GADAb but radioactive iodine (RI) therapy was carried out in five patients because of adverse effects of MMI or poor control of hyperthyroidism. The initial titer of TRAb was significantly lower in patients treated with MMI alone compared to that in RI treated patients but none of the patients treated with MMI alone went into remission after more than 3-years of follow up. We also compared these GADAb-positive patients with 14 patients with diabetes mellitus who had matched clinical features. The number of diabetic patients who remained in possible remission was significantly higher than that of GADAb-positive patients ( 5 in 14 vs 0 in 12). Moreover, the rate of remission in the diabetic patients was no different from that of 21 control patients without diabetes followed for more than 7 years ( 5 in 14 vs 7 in 21). These data suggested that GADAb-positive patients are unlikely to go into remission with antithyroid agents. Therefore, definitive therapies might be preferable for the initial treatment of GADAb-positive patients.
\end{abstract}

Key words: GAD antibody, Graves' disease, T1DM, Antithyroid agents

(Endocrine Journal 56: 269-274, 2009)

GLUTAMIC acid decarboxylase (GAD) is an enzyme that catalyzes the decarboxylation of glutamate to GABA, expressed in the pancreatic beta cells and in the brain. GAD has two isoforms, GAD65 and GAD67. GAD65, a $65 \mathrm{kDa}$ isoform, is expressed in the pancreatic beta cells and the autoantibody to GAD65 is a predictive marker for the insulin depletion in diabetes mellitus (DM) [1-3]. Autoantibody for GAD is also detectable in a number of autoimmune diseases, including type 1 diabetes mellitus (T1DM)

Received: August 25, 2008

Accepted: December 12, 2008

Correspondence to: Osamu ISOZAKI, Department of Medicine, Institute of Clinical Endocrinology, Tokyo Women's Medical University, 8-1 Kawada-cho, Shinjuku-ku, Tokyo 162-8666, Japan and autoimmune polyendocrinopathy syndrome type 1 (APS-1) [3]. It is also reported that the titer of GADAb is remarkably high and persists for a longer time in a slowly progressive form of T1DM (SPIDDM: slowly progressive insulin dependent diabetes mellitus) [4]. GADAb is also detectable in $2-8 \%$ of patients with Graves' disease (GD) without DM and $6-10 \%$ of patients with type 2 or non insulin-dependent DM $[1,5,6]$. The prevalence of GADAb in patients with these diseases is higher than that in normal population, i.e. $1-2 \%$ [5]. Of more interest the prevalence and titer of GADAb in T1DM patients are higher in patients with autoimmune thyroid diseases (AITDs) than those in patients without AITDs [6, 7]. However, the effects of GADAb on disease activities or clinical courses of AITDs are unknown. Therefore, we investigated the 
clinical characteristics of GADAb-positive patients with GD and compared the patients not only to nondiabetic GADAb-negative patients with GD but also to control diabetic patients with GD in order to clarify the effect of GADAb on remission of GD by medical therapy.

\section{Subjects and Methods}

\section{Subjects}

Twelve GD patients with GADAb (2 male, 10 female) were enrolled in this study. GADAb was measured at the onset of DM in patients with GD or at the onset of GD in patients with DM. The diagnosis of GD was confirmed by laboratory findings including elevation of serum free thyroxine (T4) and/or free triiodothyronine (T3), suppression of serum TSH, and the presence of TSH receptor antibodies (TRAb). In some cases, radioactive iodine or thyroidal uptake of ${ }^{99} \mathrm{TcO}^{-}$was carried out for validation of the diagnosis according to the diagnostic criteria of the Japan Thyroid Association [8]. We also enrolled diabetic patients with GD who was matched to the GADAbpositive patients in clinical characteristics. We also randomly selected 40 control GD patients without DM ( 8 male, 32 female) according to the data of first visit from January to June 2000. These patients were referred to the Endocrine Clinic of Tokyo Women's Medical University Hospital and were followed up by the clinic. However, some of the control GD patients were followed up by other hospitals by the patient's choice.

\section{Serum hormone and antibody determinations}

Serum free T4, free T3 and TSH were determined by automated analyzer (Roche Diagnostics K.K, Tokyo, Japan) and TSH receptor antibody (TRAb: thyrotropin binding inhibitory immunoglobulin) was determined by a commercial radioimmunoassay kit (Yamasa Shoyu Corp., Tokyo, Japan). GADAb was also determined by a commercial radioimmunoassay kit using recombinant human GAD 65 (Cosmic Corp., Tokyo, Japan) and a titer of more than 1.5 units per $\mathrm{ml}$ was judged as positive.

\section{Statistical analysis}

Differences in male-to-female ratio between the two groups were analyzed by Fisher's exact test. All data are expressed as the median \pm standard deviation or the median (minimum, maximum) as indicated. Significance between the values was determined by Student's t-test or Dunnett's test for the data with normal distribution. We employed Cox-Box transformation for the values that did not fit the normal distribution. We also used Wilcoxon/Kruskal-Wallis test for nonparametric analysis. Statistical calculations were carried out using a computer program, JMP 5.0 (SAS Institute Inc., Tokyo, Japan). We also used Fisher's exact test for comparison of remission rate between groups. P values less than 0.05 were considered significant.

\section{Results}

The male to female ratio (2/10) in GADAb positive patients were not different from that in the control patients (8/32) by Fisher's exact test. The age of onset of Graves' disease in GADAb-positive patients was not statistically different from that of control patients (42.3 \pm 16.3 vs $42.0 \pm 15.8$ years, respectively).

TRAb was positive in all patients with GADAb. The titer of TRAb at the onset of Graves' disease was similar to that of control patients $(61.7 \pm 25.4 \%$ vs $56.3 \pm 26.3 \%$, respectively).

The onset of DM was distributed from 15 years before the onset of GD to 11 years after the onset of GD and the median of the onset of DM was one year before the onset of GD as shown in Table 1. In 50\% of the patients, the difference of the onset DM was within 1.75 years; 1.0 year before to 0.75 year after the onset of GD. DM was controlled without insulin in one patient for more than 3 years.

In GADAb-positive patients, the titers of GADAb were 16.4 to $5480 \mathrm{U} / \mathrm{ml}$ (median: $232.1 \mathrm{U} / \mathrm{ml}$ ). As shown in Fig. 1, the titers of GADAb had no correlation with the titer of TRAb before treatment in these patients.

As shown in Table 1, we next classified the GADAbpositive patients into three subgroups: acute type 1 DM (AIDDM; acute insulin-dependent diabetes mellitus), slowly progressive type 1 DM (SPIDDM; slowly progressive insulin-dependent diabetes melli- 
Table 1. Clinical characteristics of GADAb-positive patients (pts) classified according to the types of DM

\begin{tabular}{lcccccc}
\hline Type of DM & \# of pts & $\begin{array}{c}\text { Gender } \\
(\mathrm{M} / \mathrm{F})\end{array}$ & $\begin{array}{c}\text { age of onset of GD } \\
(\text { year })^{\mathrm{a}}\end{array}$ & $\begin{array}{c}\text { onset of DM after GD } \\
(\text { year })^{\mathrm{a}}\end{array}$ & $\begin{array}{c}\text { GADAb } \\
(\mathrm{U} / \mathrm{ml})^{\mathrm{a}}\end{array}$ & $\begin{array}{c}\text { TRAb } \\
(\%)^{\mathrm{a}}\end{array}$ \\
\hline AIDDM & 4 & $0 / 4$ & $27.5(16,35)^{*}$ & $-2.5(-11,-1)$ & $232.1(16.4,628.5)$ & $55.75(16.6,93.5)$ \\
SPIDDM & 7 & $1 / 6$ & $47.0(30,70)$ & $0.0(-15,11)$ & $439.0(32.8,5480)$ & $62.1(37.5,97.7)$ \\
T2DM & 1 & $1 / 0$ & 64.0 & -1.0 & 41.6 & 68.3 \\
All patients & 12 & $2 / 10$ & $42.5(16,70)^{\mathrm{ns}}$ & $-1.0(15,11)$ & $232.1(16.4,5480)$ & $62.1(16.6,97.7)^{\mathrm{ns}}$ \\
\hline
\end{tabular}

GAD-positive patients were classified into three groups; acute T1DM (AIDDM), SPIDDM, and type 2 DM according the clinical course as described in results.

${ }^{\text {a }}$ The values are median (minimum, maximum).

* The value was significantly lower than that of other types of patients $(\mathrm{P}<0.05$, Dunnett's test).

ns The value was not significantly different from that of the control GD patients without DM.

Table 2. Clinical characteristics of patients treated with radioactive iodine (RI)

\begin{tabular}{|c|c|c|c|c|c|}
\hline Case \# & $\begin{array}{l}\text { Type of } \\
\text { DM }\end{array}$ & $\begin{array}{c}\text { Initial TRAb } \\
(\%)\end{array}$ & $\begin{array}{l}\text { GADAb } \\
(\mathrm{U} / \mathrm{ml})\end{array}$ & $\begin{array}{l}\text { Reasons for } \\
\text { RI therapy }\end{array}$ & $\begin{array}{l}\text { Final treatment of } \\
\text { GD }\end{array}$ \\
\hline 1 & AIDDM & 93.5 & 16.4 & liver dysfunction induced by MMI & 1-thyroxine replacement \\
\hline 2 & SPIDDM & 35.7 & 60.8 & poor control of hyperthyroidism & None \\
\hline 3 & SPIDDM & 93.7 & 122 & fever and arthralgia induced by MMI & 1-thyroxine replacement \\
\hline 4 & SPIDDM & 74.2 & 439 & poor control of hyperthyroidism & MMI \\
\hline 5 & SPIDDM & 97.7 & 1450 & poor control of hyperthyroidism & 1-thyroxine replacement \\
\hline $\begin{array}{l}\text { Sum of RI } \\
\text { treated cases }\end{array}$ & - & $\begin{array}{c}93.5 \\
(35.7,97.7)^{\mathrm{a} *}\end{array}$ & $\begin{array}{c}122 \\
(16.4,1450)^{\mathrm{ans}}\end{array}$ & - & - \\
\hline
\end{tabular}

a The values are median (minimum, maximum) of the five cases treated with radioactive iodine.

* The value was significantly higher than that of patients with GADAb who were not treated with $\mathrm{RI}(\mathrm{P}<0.05$, Student's t-test after BoxCox transformation).

ns The value was not statistically different from that of patients with GADAb who were not treated with RI.

tus), and type $2 \mathrm{DM}$ (T2DM) according the clinical courses. We defined AT1DM as a patient with acute clinical symptoms, including polyuria, polydipsia, and body weight loss and ketosis/ketoacidosis, and in whom insulin therapy was started within 3 months of the diabetic symptoms. The patient with SPIDDM was defined as a patient with T1DM whose insulin therapy was started after 3 months of the initial diabetic symptoms except ketosis/ketoacidosis. The age of onset of GD in patients with AIDDM was younger than that of other patients. However, the difference of the onset of GD and diabetes, titers of GADAb and TRAb showed no statistical difference between these subtypes.

Radioactive iodine (RI) therapy was carried out in 5 patients because of adverse effects of MMI or poor control of hyperthyroidism. In one patient hyperthyroidism deteriorated after one-year of normalization of thyroid function by RI therapy and MMI therapy was started again.
None of the patients treated with MMI alone went into remission after 36 months of therapy. However, the initial titers of TRAb in these patients (median: $49.7 \%$, range: $16.6-68.3 \%$ ) were significantly lower than those in patients treated with RI (median: $93.5 \%$, range: 35.7-97.7\%) as shown in Table $2(\mathrm{P}<0.05$, Student's t-test after Box-Cox transformation).

Next we compared these GADAb-positive patients to diabetic patients in order to clarify the impact of GADAb on outcome of GD. We enrolled 14 diabetic patients who had similar clinical characteristics to the case patients. As shown in Table 3, female to male ratio, age of onset of GD, initial TRAb titer and total follow up period with antithyroid agents were not different between the two groups. Five patients were treated with insulin and 3 patients were classified as AIDDM. None of the patients were positive for GADAb in the past. Thyroid hormone levels were normal after withdrawal of MMI for more than one year (possible remission by MMI) in 5 out of 14 dia- 
Table 3. Comparisons of GADAb-positive, diabetic and control patients (pts) with Graves' disease

\begin{tabular}{|c|c|c|c|c|}
\hline & GADAb-positive & Diabetic & Control & \\
\hline \# of pts & 12 & 14 & 40 & \\
\hline Male/Female & $2 / 10^{\mathrm{ns}}$ & $4 / 10$ & $8 / 32$ & $\begin{array}{l}{ }^{\mathrm{ns}} \text { not different from diabetic by Fisher's } \\
\text { exact test }\end{array}$ \\
\hline Age of onset of Graves' disease (year) ${ }^{\mathrm{a}}$ & $\begin{array}{c}42.5 \\
(16,70)^{\mathrm{ns}}\end{array}$ & $\begin{array}{c}42.5 \\
(18,58)\end{array}$ & $\begin{array}{c}44.5 \\
(19,80)\end{array}$ & $\begin{array}{l}\text { ns not different from diabetic by Wilcoxon/ } \\
\text { Kruskal-Wallis test }\end{array}$ \\
\hline TRAb at the onset of Graves' disease $(\%)^{\mathrm{a}}$ & $\begin{array}{c}62.10 \\
(16.6,97.7)^{\mathrm{ns}}\end{array}$ & $\begin{array}{c}69.45 \\
(26.96,107.0)\end{array}$ & $\begin{array}{c}51.22 \\
(20.12,110.0)\end{array}$ & $\begin{array}{l}\text { ns not different from diabetic by Wilcoxon/ } \\
\text { Kruskal-Wallis test }\end{array}$ \\
\hline Types of $\mathrm{DM}^{\mathrm{b}}$ & $4 / 7 / 1$ & $3 / 0 / 11$ & - & ${ }^{\mathrm{b}}$ indicate \# of pts AIDDM/SPIDDM/T2DM \\
\hline Therapy (Tx) for $\mathrm{DM}^{\mathrm{c}}$ & $11 / 0 / 1$ & $5 / 7 / 2$ & - & ${ }^{\mathrm{c}}$ indicates \# of pts in insulin/drug/diet Tx \\
\hline Onset of DM after or before Graves (year) ${ }^{\mathrm{a}}$ & $\begin{array}{l}-1.0 \\
(-15,11)^{\mathrm{ns}}\end{array}$ & $\begin{array}{c}-1.25 \\
(-10,20)\end{array}$ & - & $\begin{array}{l}\text { ns not different from diabetic by Wilcoxon/ } \\
\text { Kruskal-Wallis test }\end{array}$ \\
\hline Final treatment of GD (MMI / RI/ Operation $)^{\mathrm{d}}$ & $7 / 5 / 0$ & $13 / 1 / 0$ & $16 / 4 / 1^{\$}$ & $\begin{array}{l}\mathrm{d} \text { indicate \# of pts in MMI / RI/ Operation } \\
\$ 19 \text { pts were missed during follow up }\end{array}$ \\
\hline \# of pts in possible remission & $0 / 12 *$ & $5 / 14^{\mathrm{ns}}$ & $7 / 21$ & $\begin{array}{l}\text { * different from diabetic and }{ }^{\text {ns }} \text { not different } \\
\text { from control by Fisher's exact test }\end{array}$ \\
\hline Duration of MMI therapy (year) ${ }^{\mathrm{a}}$ & $\begin{array}{l}4.0 \\
(3,7)^{\mathrm{ns}}\end{array}$ & $\begin{array}{c}6.0 \\
(1,12)\end{array}$ & $\begin{array}{c}7.0 \\
(7,8)\end{array}$ & $\begin{array}{l}{ }^{\mathrm{ns}} \text { not different from diabetic by Wilcoxon/ } \\
\text { Kruskal-Wallis test }\end{array}$ \\
\hline
\end{tabular}

a The values are median (minimum, maximum).

\section{$\operatorname{GADAb}(\mathrm{U} / \mathrm{ml})$}

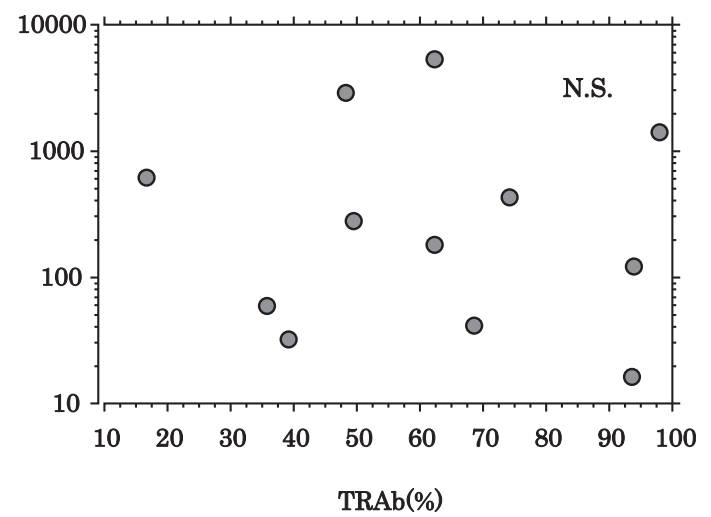

Fig. 1. Relationship between GADAb and TRAb in GADAbpositive patients with GD. The initial titer of TRAb before therapy was expressed as \% of inhibition according to the manufacture of the radio-receptor assay kit. Titer of GADAb as U/ml was expressed in log scale. Linear regression analysis was conducted between the Box-Cox transformed titers of TRAb and GADAb as described. The analysis did not show any significant correlation between the titers.

betic patients. Therefore the possible remission rate by MMI was significantly lower in GADAb-positive GD patients compared to that in diabetic patients $(0$ in 12 vs 5 in 14, $\mathrm{P}<0.05$ in Fisher's exact test). On the other hand, the number of diabetic patients who went into possible remission was similar to that of control patients without DM after 7-year-follow up (5 in 14 vs 7 in 21, P $>0.05$ in Fisher's exact test).

\section{Discussion}

The presence of GD and T1DM in the same subject is not usual, but the molecular etiology for this condition has been identified in only a small number of patients such as APS-1 [3]. One Japanese study on GADAb in patients with both GD and T1DM suggests a close immunological relationship between the two diseases in one patient rather than an incidental complication [9]. In support of this close immunological relationship hypothesis, their study showed that the onset of GD and T1DM was simultaneous in 6 out of 14 patients, and that the onset of GD was earlier in 8 out of their 14 patients with GADAb. In our study, the difference of onset of GD and DM was less than one year in $50 \%$ of the patients with GADAb. These data also support the close immunological relationship theory. However, it should be remembered that these observations do not necessarily suggest simultaneous 
development of DM and GD in GADAb-positive patients because we measured GADAb only at the onset of DM in GD patients and at the onset of GD in diabetic patients. Therefore, patients who used to have GADAb only at the onset of DM may have been overlooked in this study, which is often observed in patients with the acute type of T1DM [4]. However, GADAb in patients with GD may suggest the presence of common contributing factors in the pathogenesis of $\mathrm{DM}$ and GD in these patients.

The relatively higher titer of GADAb in our GADAbpositive patients is compatible with previous reports on GADAb in patients with autoimmune thyroid diseases $[5,6]$. However, the titer of TRAb at the onset of GD was similar in both groups and had no correlation with the titer of GADAb. These observations suggest that the production of GADAb and TRAb may be regulated at least partially by some common mechanisms but not by the same mechanism in these patients. These data are also compatible with a previous report [9].

The observation that none of the GADAb-positive patients in our study went into remission with MMI therapy in spite of the lower titer of TRAb compared to that in patients treated with RI also suggested that GADAb itself had no effect on initial disease activities of GD, but that disease activity in patients with GADAb may persist for long periods. A similar observation is also reported in GD patients with SPIDDM [4]. They reported that eight GD patients with GADAb (titer more than $40 \mathrm{U} / \mathrm{ml}$ ) before therapy had higher titers of both GADAb and TRAb after 6-year-treatment with MMI [10]. They therefore recommended RI therapy or subtotal thyroidectomy for GD patients with high titer of GADAb. Compatible with the previous report the number of patients who went into remission in the present study was significantly less in GADAb positive patients compared to that in control diabetic patients.

Persistence of the disease activity of GD in GADAbpositive patients may also be suggested by the fact that the titer of GADAb itself is sustained for a prolonged period in some diabetic patients. GADAb in SPIDDM is usually higher in titer and it is sustained in higher titer for longer periods compared to that in AIDDM $[4,10]$. Sustained high titer of GADAb is also report- ed in T1DM patients with AITD [6]. Moreover, a recent study revealed that the epitope regions of GADAb in SPIDDM are different from that in AIDDM [11]. Therefore, the epitope regions of GADAb in patients with AITD may different from those in patients without AITD, and the difference of GADAb might contribute not only to the higher titer of GADAb but also to the sustained GADAb production. However, there is no data about the difference of epitope of GADAb in GD patients so far.

The sustained activity of GD in GADAb-positive patients may be explained by genetic markers related to autoimmunity. According to previous reports the frequency of GG genotype or G allele at position 49 of CTLA-4 polymorphism is significantly higher in GADAb-positive patients with both GD and TIDM compared to GADAb-negative patients $[9,12]$. With respect to the CTLA-4 polymorphism, one study demonstrated that the GG genotype is associated with significantly longer time until remission with antithyroid drugs [13]. Taken together, it is reasonable to assume that GADAb in GD patients may be a possible marker indicating the unlikelihood of going into remission with antithyroid agents.

Recently Miya et al. reported a case of SPIDDM and GD which was complicated with MMI-induced liver dysfunction and agranulocytosis [14]. We have no evidence to indicate that GADAb may increase the incidence of adverse reaction to MMI, but RI therapy might be preferable in patients who should continue to take antithyroid agents for a prolonged period in order to avoid the adverse effects of antithyroid agents. The fact that we should abandon MMI-therapy in two out of 12 patients because of its adverse effects also supports the choice of definitive therapy as initial treatment. Therefore, definitive therapy might be preferable for GD in T1DM patients with GADAb.

In sum, this study suggested that GD patients with GADAb are unlikely to go into remission with antithyroid therapy. Therefore, definitive therapies might be preferable for these patients at the start of therapy. However, prospective studies with longer observation periods and with larger numbers of patients with or without GADAb are necessary to clarify the exact role of GADAb in GD. 


\section{References}

1. Turner R, Stratton I, Horton V, Manley S, Zimmet P, Mackay IR, Shattock M, Bottazzo GF, Holman R (1997) UKPDS 25: autoantibodies to islet-cell cytoplasm and glutamic acid decarboxylase for prediction of insulin requirement in type 2 diabetes. UK Prospective Diabetes Study Group. Lancet 350: 1288-1293.

2. Leslie RD, Atkinson MA, Notkins AL (1999) Autoantigens IA-2 and GAD in Type I (insulin-dependent) diabetes. Diabetologia 42: 3-14.

3. Barker JM (2006) Clinical review: Type 1 diabetesassociated autoimmunity: natural history, genetic associations, and screening. J Clin Endocrinol Metab 91: 1210-1217.

4. Kobayashi T, Nakanishi K, Okubo M, Murase T, Kosaka K (1996) GAD antibodies seldom disappear in slowly progressive IDDM. Diabetes Care 19: 1031.

5. Hiromatsu Y, Mukai T, Kaku H, Miyake I, Ichimura M, Fukutani T, Nakayama H, Takata K, Imamura Y, Shoji S, Yamada K, Koda Y, Bednarczuk T (2006) IL-18 gene polymorphism confers susceptibility to the development of anti-GAD65 antibody in Graves' disease. Diabet Med 23: 211-215.

6. Kawasaki E, Takino H, Yano M, Uotani S, Matsumoto K, Takao Y, Yamaguchi Y, Akazawa S, Nagataki S (1994) Autoantibodies to glutamic acid decarboxylase in patients with IDDM and autoimmune thyroid disease. Diabetes 43: 80-86.

7. Akawaza S, Kawasaki E, Yano M, Abiru N, Yamaguchi Y, Nagataki S (1994) Autoantibodies to glutamic acid decarboxylase (GAD), 64,000-Mr islet cell protein $(64 \mathrm{~K})$ antibodies and islet cell antibodies (ICA) in insulin-dependent diabetes mellitus with and without autoimmune diseases in Japan. Diabetes Res Clin Pract 24 Suppl: S89-93.

8. Japan Thyroid Association (2008) Guidelines for the Diagnosis of Graves' disease. http://thyroid.umin.ac.jp/ en/guidelines/index.html.
9. Kusaka I, Nagasaka S, Fujibayashi K, Hayashi H, Kawakami A, Nakamura T, Rokkaku K, Saito T, Higashiyama M, Honda K, Ishikawa S, Saito T (1999) Immunologically-related or incidental coexistence of diabetes mellitus and Graves' disease; discrimination by anti-GAD antibody measurement. Endocr $J$ 46: 747-754.

10. Toyoda N, Nomura E, Iwasaka T, Nishikawa M (2007) Outcome of antithyroid drug therapy in Graves' disease accompanied with Type 1 DM. Folia Endocrinologica Japonica 83: 102 (in Japanese).

11. Kobayashi T, Tanaka S, Okubo M, Nakanishi K, Murase T, Lernmark A (2003) Unique epitopes of glutamic acid decarboxylase autoantibodies in slowly progressive type 1 diabetes. J Clin Endocrinol Metab 88: 4768-4775.

12. Ikegami H, Awata $\mathrm{T}$, Kawasaki E, Kobayashi $\mathrm{T}$, Maruyama T, Nakanishi K, Shimada A, Amemiya S, Kawabata Y, Kurihara S, Tanaka S, Kanazawa Y, Mochizuki M, Ogihara T (2006) The association of CTLA4 polymorphism with type 1 diabetes is concentrated in patients complicated with autoimmune thyroid disease: a multicenter collaborative study in Japan. J Clin Endocrinol Metab 91: 1087-1092.

13. Kinjo Y, Takasu N, Komiya I, Tomoyose T, Takara M, Kouki T, Shimajiri Y, Yabiku K, Yoshimura H (2002) Remission of Graves' hyperthyroidism and A/G polymorphism at position 49 in exon 1 of cytotoxic $\mathrm{T}$ lymphocyte-associated molecule-4 gene. J Clin Endocrinol Metab 87: 2593-2596.

14. Miya K, Takizawa H, Kanezaki T, Yoshida T, Abe Y, Shintani H (2007) A patient with Graves' disease simultaneous onset of type $1 \mathrm{DM}$ who was complicated with agranulocytosis due to antithyroid agent and finally subjected to subtotal thyroidectomy. Tokushima Red Cross Hospital Medical Journal 12: 93-99 (in Japanese). 